\title{
Nanocrystalline silicon thin films on PEN substrates
}

\author{
F. Villar, J. Escarré, A. Antony, M. Stella, F. Rojas, J. M. Asensi, J. Bertomeu, J. Andreu
}

Universitat de Barcelona, Departament de Física Aplicada i Òptica, Av. Diagonal 647, E08028 Barcelona

\begin{abstract}
We study the structural and electrical properties of intrinsic layers growth close to the transition between amorphous silicon (a-Si:H) and nanocrystalline silicon (nc-Si:H) deposited on glass and PEN without intentional heating. These samples showed different behaviour in Raman shift and XRD spectra when compared with that of samples deposited at $200^{\circ} \mathrm{C}$. Electrical properties of these films also reflect the transition between a-Si:H and nc-Si:H, and put in evidence some differences between the microstructure of the films grown on PEN and on glass.

P- and n-doped layers were deposited onto glass substrates without intentional heating and at $100^{\circ} \mathrm{C}$ with thicknesses ranging from $1000 \mathrm{~nm}$ to $35 \mathrm{~nm}$. Conductivity measurements indicate the capability of doping this material, but, for very thin layers, substrate heating was found to be essential.
\end{abstract}

\section{Keywords}

Hot-wire deposition, Solar cell, plastic substrates.

\section{Introduction}

The high cost of production for c-Si based solar cells has increased the interest of the scientific community to look for low cost thin film solar cells based on amorphous silicon 
(a-Si:H) and nanocrystalline silicon (nc-Si:H). These thin-film based solar cells need a lower amount of material, thus reducing the total cost of the solar cell production, without compromising their efficiency. Another advantage of these thin-film solar cells is the possibility for roll-to-roll deposition onto flexible substrates, which again reduces the cost of production [1]. The use of polymeric flexible substrates imposes some restrictions on the deposition parameters, mainly the low substrate temperature in all the processes of the thinfilm solar cells fabrication. Hot-Wire Chemical Vapour Deposition (HW-CVD) technique is suitable to deposit at low temperature due to the possibility of high hydrogen dilution process that leads to the growth of nc-Si:H material without any additional substrate heating.

In this work, we test the viability of the use of polyethylene naphthalene (PEN) as a substrate for n-i-p solar cells. In previous works, we demonstrated the possibility to deposit ZnO:Al on this substrate at very low substrate temperature with good electrical and optical properties [2].

\section{Experimental}

Intrinsic thin silicon layers with thicknesses ranging from 300 to $1000 \mathrm{~nm}$ were deposited onto Corning 1737 glass and on PEN (150 $\mu$ m thickness) in a HW-CVD set-up as described elsewhere [3]. Dissociation of the gases was achieved by means of two $0.5 \mathrm{~mm}$ diameter Ta filaments, which were resistively heated up to $1650{ }^{\circ} \mathrm{C}$. The samples were deposited without any intentional substrate heating. The temperature measured with a thermocouple attached to the glass substrate evolved when the shutter was opened as shown in Fig 1. To prevent exceeding the maximum working temperature of the polymer (about $160^{\circ} \mathrm{C}$ ) the deposition time was kept below 30 min. The transition from a-Si:H to nc-Si:H was achieved by decreasing the process pressure from 8 to $1 \mathrm{~Pa}$.

Doped layers, with thicknesses varying from 35 to $1000 \mathrm{~nm}$, were obtained by adding certain amount of diborane or phosphine gas to the silane-hydrogen gas mixture. These 
samples were deposited onto Corning 1737 without intentional substrate heating and for the thinner ones also with previous heating at $100^{\circ} \mathrm{C}$ or $50^{\circ} \mathrm{C}$.

The thickness of the samples was measured with a profilometer and their microstructure was analysed by Raman spectroscopy. The crystalline fraction defined as $X_{\mathrm{c}}=\left(I_{520}+I_{510}\right) /\left(I_{520}+I_{510}+I_{480}\right)$ was deduced by deconvolution of the spectra into three Gaussian bands. The peaks located at 520 and $510 \mathrm{~cm}^{-1}$ were attributed to crystalline phases and the one at $480 \mathrm{~cm}^{-1}$ to the disordered phase [4]. Differences in preferential orientation, stress and crystallite sizes were obtained from X-Ray Diffraction (XRD). Four rectangular aluminium contacts were deposited on the layers for the electrical measurements. The photoconductivity measurements were carried out by illuminating the sample with a halogen lamp which is calibrated at $100 \mathrm{~mW} / \mathrm{cm}^{2}$.

\section{Results and discussion}

\section{$\underline{3.1 \text { Intrinsic layers }}$}

The Raman spectra of the intrinsic layers on glass and PEN substrates are shown in Fig 2 together with the intrinsic layer deposited at $200^{\circ} \mathrm{C}$ on glass. A very abrupt transition of the samples from a-Si:H to nc-Si:H can be observed. Only by varying the process pressure from 4 to $6 \mathrm{~Pa}$, samples without crystalline contribution or with $X_{\mathrm{c}}$ around 0.7 can be obtained.

On the other hand, the position of the crystalline contribution of the Raman spectra usually localized at $520 \mathrm{~cm}^{-1}$ in the literature- exhibited a shift for the samples deposited without intentional heating. This behaviour can be attributed either to differences in stress [5] or to a variation of the crystallite sizes $\left(L_{C}\right)$ [6] of the samples. From the analyses of the XRD spectra, the variations in the lattice parameter were not large enough to produce such shifts in Raman peaks. In this way, the shift in the Raman spectra must be due to the smaller crystallite sizes of the samples. Accordingly, one can estimate the mean size of the crystallites using a relation between the downshift $(\Delta \omega)$ and $L_{C}$ based on bond polarizability model which gives $L_{\mathrm{C}} \sim 2.5-3.5 \mathrm{~nm}$ [6]. The samples on PEN exhibited lower shifts in the Raman spectra. This 
suggests that larger crystallite sizes are obtained on PEN. This could be related to the fact that the surface temperature of the PEN substrate increases faster than that of the glass substrate upon filament exposure.

In Fig 3 the dark conductivity $\left(\sigma_{D}\right)$ and photosensitivity $(S)$ of the samples are plotted against the pressure. Similar behaviour was found for both substrates in the transition from nc-Si:H to a-Si:H, when deposition pressure is increased. The layers grown on PEN, in spite of their lower $X_{c}$ values in front of the samples on glass, exhibited slightly higher values for dark conductivity $\left(\sigma_{D}\right)$, which may be due to the larger crystallite sizes as mentioned above.

\subsection{Doped layers}

Measurements of the conductivity of the both n- and p-doped layers deposited at different process conditions as a function of the thickness are shown in Fig. 4. Both types of doped samples showed a strong dependence in conductivity with the thickness of the film. For samples deposited without intentional heating and with thickness below $100 \mathrm{~nm}$, the conductivity decreased drastically. This suggests an a-Si:H layer incubation for this kind of material that makes difficult its doping. In order to check this behaviour we deposited intrinsic samples with the same conditions and different thicknesses. The Raman evolution of these samples is plotted in Fig 5a. An a-Si:H layer nearly of $400 \mathrm{~nm}$ was found in contrast with samples deposited at $200^{\circ} \mathrm{C}$ that exhibited a nc-Si:H growth from the substrate as reported previously [7].

To avoid this problem, we deposited samples with pre-heating of the substrate at temperatures of $100^{\circ} \mathrm{C}$ and $50^{\circ} \mathrm{C}$. The conductivities of these samples are also presented in Fig 4. In Fig 5b the Raman spectra of the samples showing the highest conductivity values are shown. We have succeeded in depositing a thin n-doped layer $(65 \mathrm{~nm})$ on PEN at a substrate temperature of $50^{\circ} \mathrm{C}$ with a conductivity of $11.8 \Omega^{-1} \cdot \mathrm{cm}^{-1}$. Further work will deal with the optimisation of thin p-doped layers on PEN. 


\section{Conclusions}

Intrinsic and doped layers were deposited by HWCVD onto glass and PEN substrates. The layers deposited without any intentional substrate heating were studied and compared with those deposited at $200^{\circ} \mathrm{C}$. A smaller crystallite size for the samples deposited without intentional heating was found. In the case of samples deposited on PEN the crystallite size is larger than for the samples deposited on glass under the same conditions, and also showed higher conductivity values.

For doped films thinner than $100 \mathrm{~nm}$, a pre-heating of the substrate was required to obtain a crystalline growth from the substrate, thus allowing the doping efficiency. We have succeeded grown a $65 \mathrm{~nm}$ n-layer on $\mathrm{PEN}$ at low substrate temperature of $50^{\circ} \mathrm{C}$ with conductivity of $11.8(\Omega \cdot \mathrm{cm})^{-1}$.

\section{Acknowledgments}

This work has been supported by the EU through the FLEXCELLENCE project (contract 019948) and the Spanish Government (ENE2004-07376-C03-01 and ENE2005-25268-E).

\section{References}

[1] J. Bailat, V. Terrazzoni-Daudrix, J. Guillet, F. Freitas, X. Niquille, A. Shah, C. Ballif, T. Scharf, R.Morf, A. Hansen, D. Fischer, Y. Ziegler, A. Closset Proceedings of the 20th EU Photovoltaic Solar Energy Conference, ISBN 3-936338-19-1, WIP Renewable Energies, pp. 1529-1532, 2005.

[2] M. Fonrodona, J. Escarré, F. Villar, D. Soler, J.M. Asensi, J. Bertomeu and J. Andreu. Sol. Energy Mater. Sol. Cells 89 (2005) 37

[3] C. Voz, D. Peiró, J. Bertomeu, D. Soler, M. Fonrodona, J. Andreu, Mater. Sci. Eng. B 69/70 (2000) 278. 
[4] L. Houben, M. Luysberg, P. Hapke, R. Carius, F. Finger, H. Wagner, Philos. Mag A 77 (6) (1998) 1447.

[5] I. De Wolf, Semicond. Sci. Technol. 11, (1996) 139.

[6] J. Zi, H. Büscher, C. Falter, W. Ludwig, K. Zhang and X. Xie. Appl. Phys. Lett. 69 (1996) 200.

[7] M. Fonrodona, D. Soler, J.M. Asensi, J. Bertomeu and J. Andreu, J. Non-Cryst. Solids 299-302 (2002), p. 14 


\section{Figure captions}

Fig. 1. Evolution of the substrate temperature as a function of the time due to filament exposure. The shutter was opened at $\mathrm{t}=5 \mathrm{~min}$.

Fig. 2. Raman spectra of the intrinsic layers deposited without intentional heating (WIH) on glass and PEN substrates compared with those deposited at $200{ }^{\circ} \mathrm{C}$.

Fig. 3. Dark conductivity $\left(\sigma_{\mathrm{D}}\right)$ and photosensitivity (S) at room temperature of the intrinsic layers on glass and PEN deposited without intentional substrate heating.

Fig. 4. Dark conductivity at room temperature for doped layers prepared with different deposition parameters in function of the thickness of the sample.

Fig. 5. a) Raman spectra of layers deposited without intentional heating with different thicknesses and at the same deposition conditions. b) Raman spectra of very thin doped layers. 


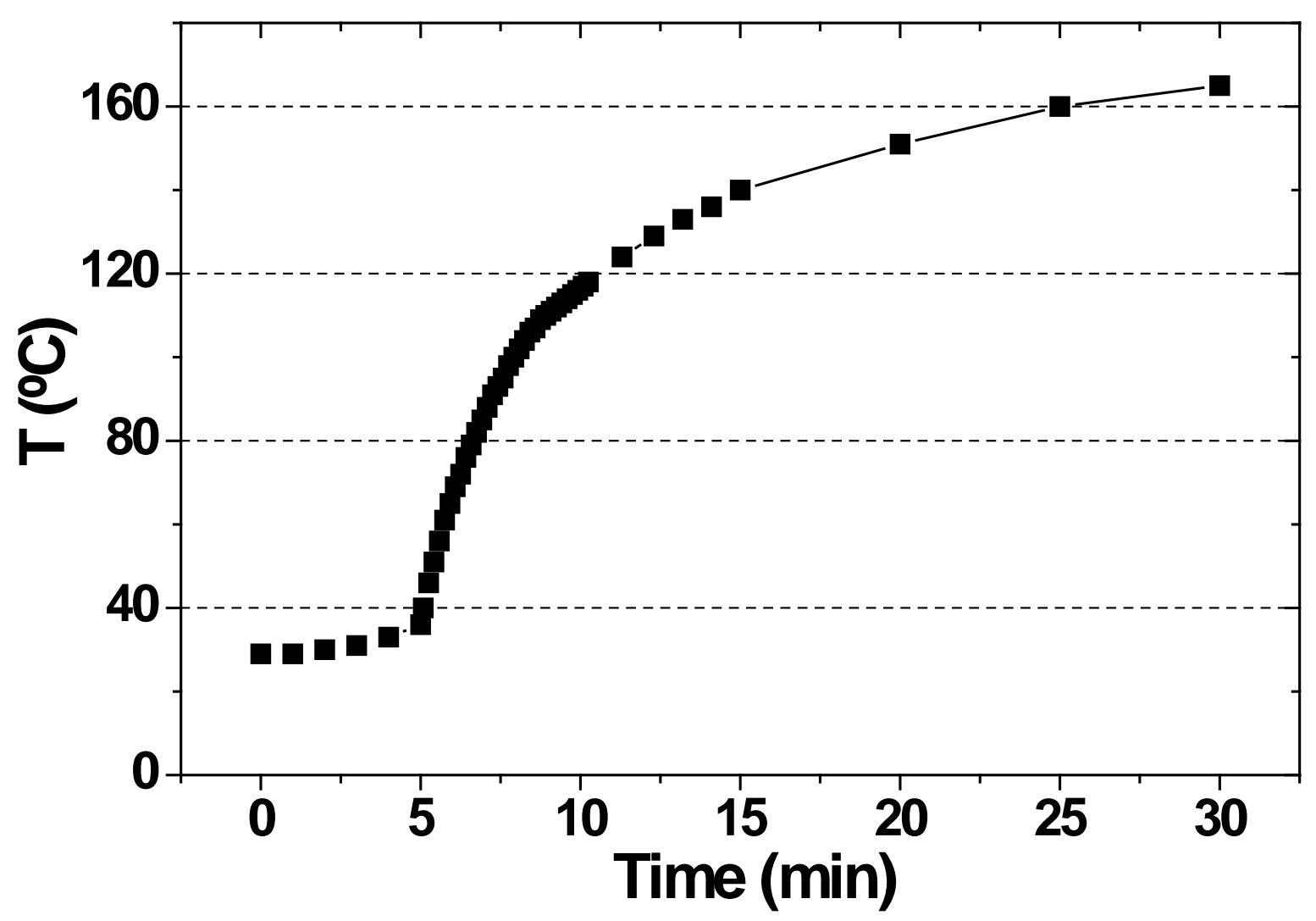




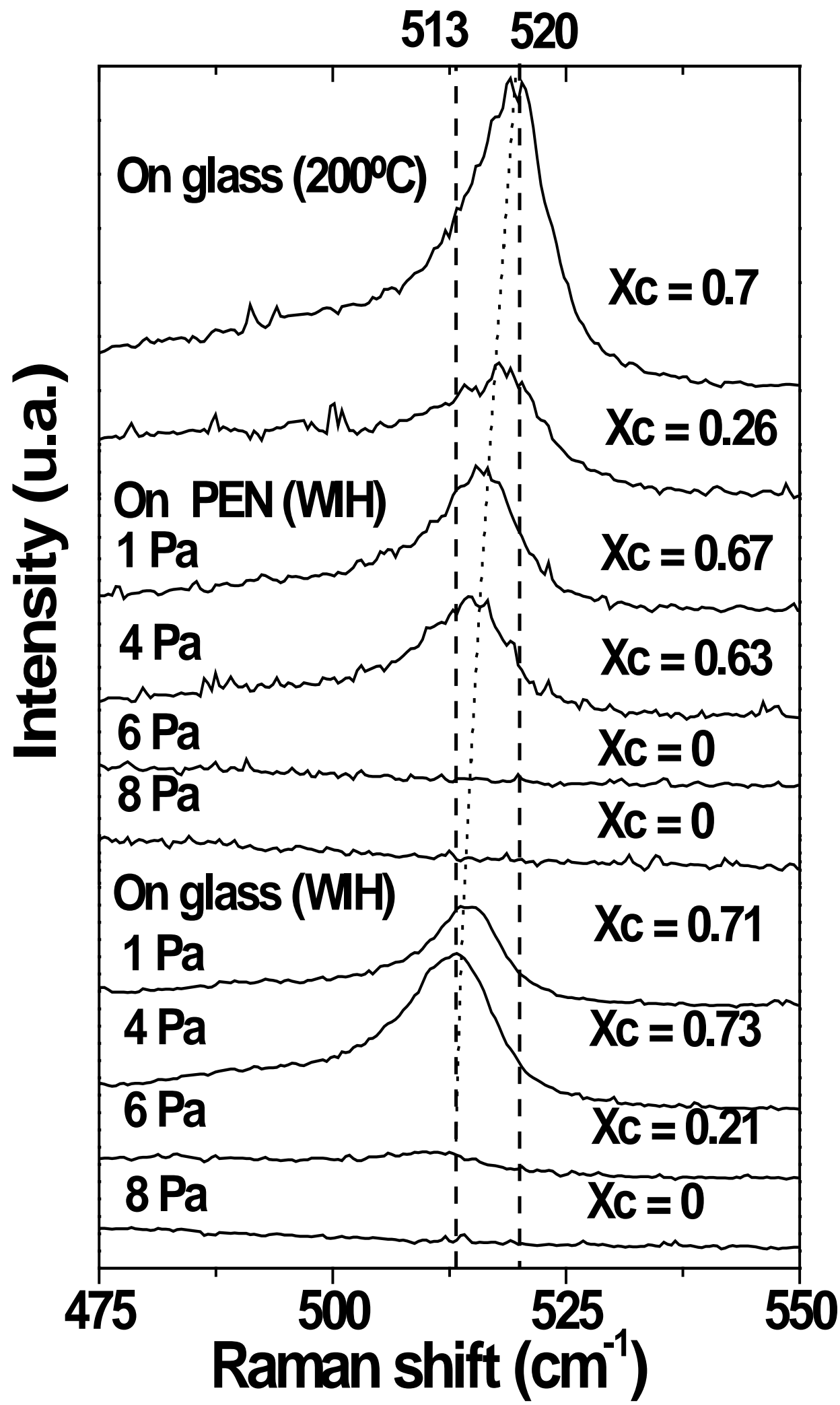




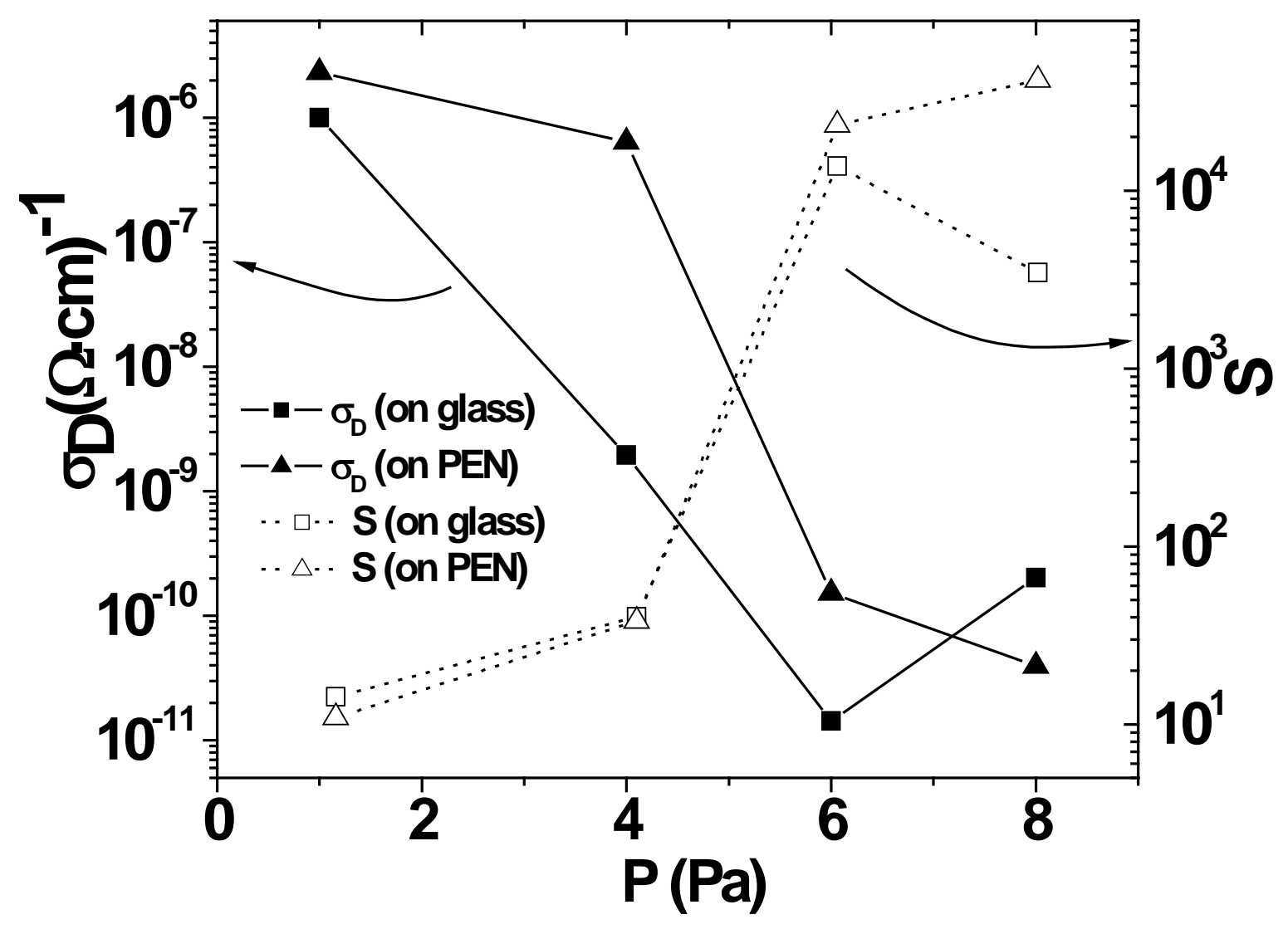




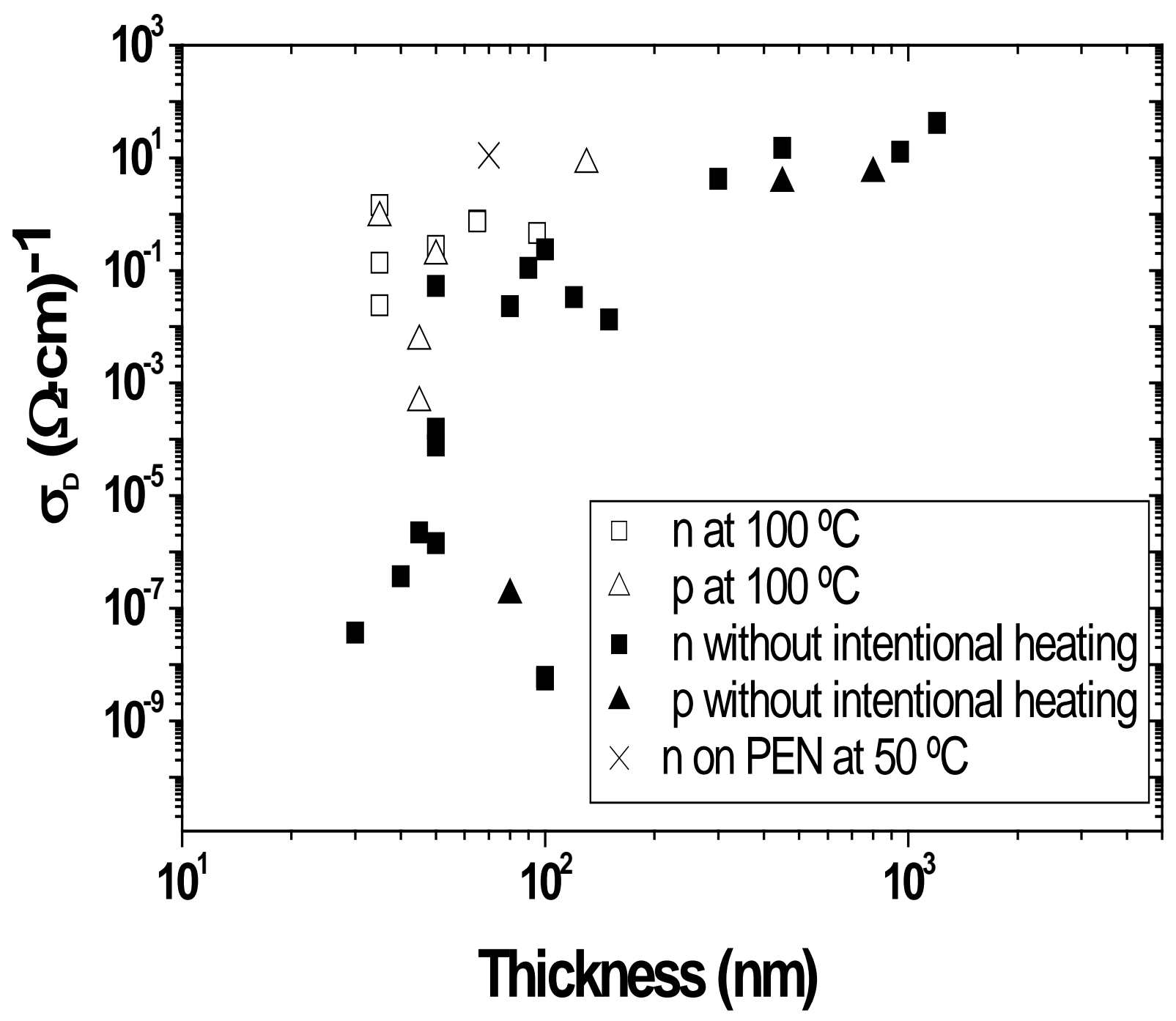




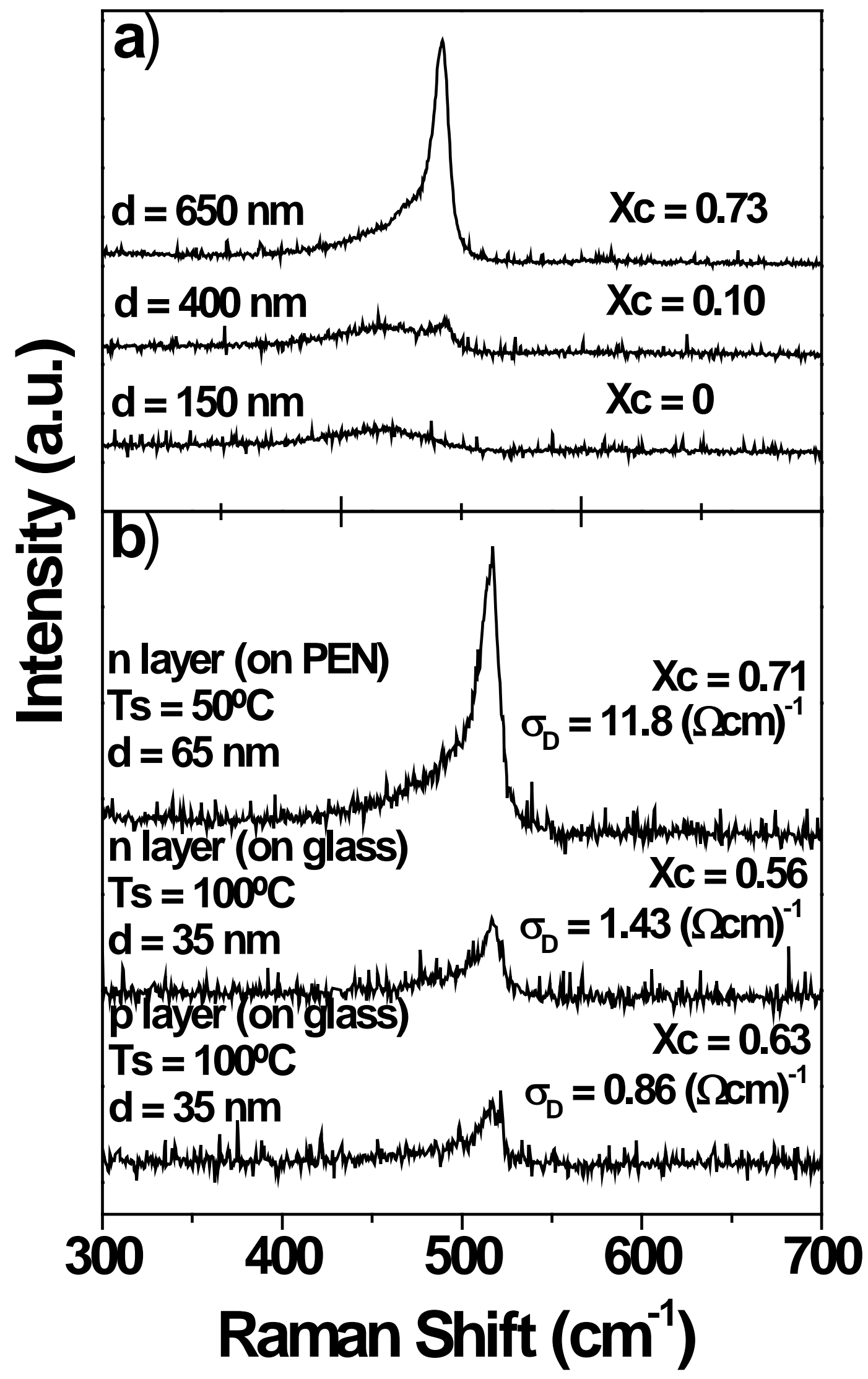

